\title{
Medical Comorbidity in Schizophrenia
}

To the Editor:- We read with interest the article by Carney et al. ${ }^{1}$ on the association of schizophrenia with other medical illnesses. In reality, the migration of psychiatric patients into general Internal Medicine practice has been progressively increasing since the deinstitutionalization of the severely mentally ill over 40 years ago. At Denver Health, a large vertically integrated public safety net hospital system, we responded to this phenomenon almost 10 years ago by establishing clinics within our Internal Medicine practices, specifically geared to caring for the complex medical comorbidities of severely mentally ill patients. ${ }^{2,3}$ A key component to our clinics is having 1 provider with interest in the population who can bridge communication with mental health providers and facilitate care coordination. This initiative was also spawned because we often treated these patients when their disease process had advanced beyond when it should have been treated. These patients are often reticent to seek timely medical care caused by their inherent paranoia, the stigma they have perceived when seeking care previously, and as the editorial on Carney's article points out, "for patients with schizophrenia, negotiating a separate complex, medical health care system can be challenging..." Although there is an increasing need for General Internists to became more familiar with prescribing psychiatric medication, as services for mental health patients continue to shrink, ${ }^{5}$ this perhaps should be limited to the care of the less complex mental health patient who also has medical comorbidities. However, for those patients with severe and persistent complex mental illness, our model of designating some Internists, with a special interest in these patients and clinic times solely for the care of these patients, may ultimately be the most efficient and tenable manner to attend to their mental health and medical needs. This in turn may avert the impediments that challenge the health of these patients and minimize the impact on health care systems, which by default must provide the care.

Philip S. Mehler, MD, Denver Health Medical Center, 660 Bannock Street, MC 0278, Denver, CO 80204, USA; (e-mail: David.bekelman@UCHSC.edu); Cynthia K. Crews, MD, Thomas Mackenzie, MD, Department of General Internal Medicine, Denver Health Medical Center, Denver, CO, USA.

\section{REFERENCES}

1. Carney CP, Jones L, Woolson RF. Medical comorbidities in women and men with schizophrenia. J Gen Intern Med. 2006;21:1133-7.

2. Crews C, Batal H, Elasy TA, Casper E, Mehler PS. Primary Care for those with severe and persistent mental illness. West J Med. 1998;169:245-50.

3. Crews CK, Vu KO, Davidson AJ, Crane LA, Mehler PS, Steiner JF. Podiatric problems are associated with worse health status in persons with severe mental illness. Gen Hosp Psych. 2004;26:226-32.

4. Misra S, Ganzini L. Medical care for patients with severe and persistent mental illness. J Gen Intern Med. 2006;21:1207-8.

5. Mackenzie TD, Kolpak SJ, Mehler PS. Prevalence and treatment of mental disorders. N Engl J Med. 2005;353(11):1184.

(C) 2007 Society of General Internal Medicine 2007;22:1063

DOI: $10.1007 /$ s11606-007-0219-Z

Published online May 3, 2007 